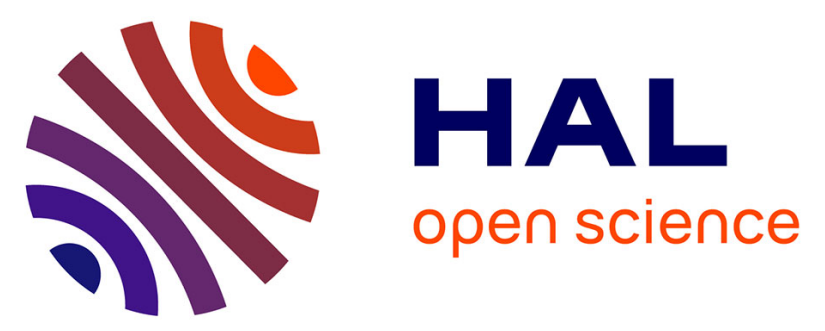

\title{
Effects of the nature of the doping salt and of the thermal pre-treatment and sintering temperature on spark plasma sintering of transparent alumina
}

Nicolas Roussel, Lucile Lallemant, Bernard Durand, Sophie Guillemet, Jean-Yves Chane Ching, Gilbert Fantozzi, Vincent Garnier, Guillaume Bonnefont

\section{To cite this version:}

Nicolas Roussel, Lucile Lallemant, Bernard Durand, Sophie Guillemet, Jean-Yves Chane Ching, et al.. Effects of the nature of the doping salt and of the thermal pre-treatment and sintering temperature on spark plasma sintering of transparent alumina. Ceramics International, 2011, vol. 37, pp. 3565-3573. 10.1016/j.ceramint.2011.05.152 . hal-00859670

\section{HAL Id: hal-00859670 https://hal.science/hal-00859670}

Submitted on 9 Sep 2013

HAL is a multi-disciplinary open access archive for the deposit and dissemination of scientific research documents, whether they are published or not. The documents may come from teaching and research institutions in France or abroad, or from public or private research centers.
L'archive ouverte pluridisciplinaire HAL, est destinée au dépôt et à la diffusion de documents scientifiques de niveau recherche, publiés ou non, émanant des établissements d'enseignement et de recherche français ou étrangers, des laboratoires publics ou privés. 


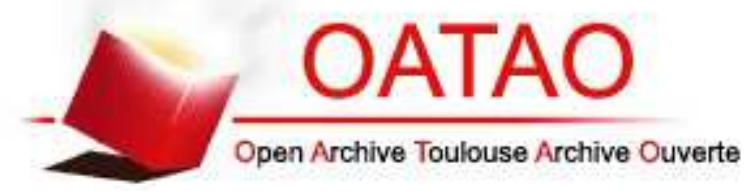

\section{Open Archive TOULOUSE Archive Ouverte (OATAO)}

OATAO is an open access repository that collects the work of Toulouse researchers and makes it freely available over the web where possible.

This is an author-deposited version published in : http://oatao.univ-toulouse.fr/ Eprints ID : 8689

To link to this article : DOI:10.1016/j.ceramint.2011.05.152

URL : http://dx.doi.org/10.1016/j.ceramint.2011.05.152

To cite this version : Roussel, Nicolas and Lallemant, Lucile and Durand, Bernard and Guillemet, Sophie and Ching, Jean-Yves Chane andFantozzi, Gilbert and Garnier, Vincent and Bonnefont, Guillaume Effects of the nature of the doping salt and of the thermal pre-treatment and sintering temperature on spark plasma sintering of transparent alumina. (2011) Ceramics International, vol. 37 ( $\left.{ }^{\circ} 8\right)$. pp. 3565-3573. ISSN 0272-8842

Any correspondance concerning this service should be sent to the repository administrator: staff-oatao@ listes-diff.inp-toulouse.fr 


\title{
Effects of the nature of the doping salt and of the thermal pre-treatment and sintering temperature on Spark Plasma Sintering of transparent alumina
}

\author{
Nicolas Roussel $^{\text {a }}$, Lucile Lallemant ${ }^{\mathrm{b}, \mathrm{c}}$, Bernard Durand ${ }^{\mathrm{a}, *}$, Sophie Guillemet ${ }^{\mathrm{a}}$, \\ Jean-Yves Chane Ching ${ }^{\mathrm{a}}$, Gilbert Fantozzi ${ }^{\mathrm{b}, \mathrm{c}}$, Vincent Garnier ${ }^{\mathrm{b}, \mathrm{c}}$, Guillaume Bonnefont ${ }^{\mathrm{b}, \mathrm{c}}$ \\ ${ }^{\text {a } C I R I M A T, ~ U M R ~ C N R S ~ 5085, ~ U n i v e r s i t e ́ ~ P a u l ~ S a b a t i e r ~-~} 118$ route de Narbonne - F-31062 TOULOUSE Cedex 9, France \\ ${ }^{\mathrm{b}}$ Université de Lyon, CNRS, France \\ ${ }^{\mathrm{c}}$ INSA-Lyon, MATEIS UMR5510, F-69621 Villeurbanne, France
}

\begin{abstract}
A slurry of $\alpha-\mathrm{Al}_{2} \mathrm{O}_{3}$ was doped with $\mathrm{Mg}, \mathrm{Zr}$ and La nitrates or chlorides, in various amounts in the range $150-500$ wt ppm and then freeze-dried to produce nanosized doped powder $(\sim 150 \mathrm{~nm})$. The powder was sintered by SPS to yield transparent polycrystalline alpha alumina. The influence of the nature of the doping element and the starting salt, the thermal treatment before sintering and the sintering temperature on the transparency of the ceramics were investigated. The transparency of the ceramics of nanosized $\mathrm{Al}_{2} \mathrm{O}_{3}$ was shown to depend mainly on the way the powder was prepared,thenatureofthedopingsaltalsohadaneffect.Finally, ahighrealinlinetransmittance, reaching $48.1 \%$ wasachievedafteroptimization.
\end{abstract}

Keywords: B. Grain size; B. Porosity; C. Optical properties; D. $\mathrm{Al}_{2} \mathrm{O}_{3}$; Doping; Spark Plasma Sintering

\section{Introduction}

For both mechanical and economical reasons, numerous studies have been performed over recent years to replace sapphire by transparent polycrystalline alumina (PCA) in various optical applications such as discharge lamp envelopes and optical windows or armour [1-5]. The light transmission properties of fine-grained PCA can be described by the Apetz and van Bruggen model [6], based on the Rayleigh-GansDebye approximation. The real inline transmittance (RIT) is strongly dependent on grain size (i.e. light scattering by grain boundaries $\gamma_{G}$ ) and porosity (i.e. light scattering by pores $\gamma_{p}$ ) as can be seen from the following equations:

$$
\begin{aligned}
& \operatorname{RIT}=\frac{I_{2}}{I_{1}}=\left(1-R_{s}\right) \cdot \exp \left(-\gamma_{\mathrm{tot}} \cdot D\right) \\
& \gamma_{\mathrm{tot}}=\gamma_{G}+\gamma_{p}=\frac{3 \pi^{2} r \Delta n^{2}}{\lambda_{0}^{2}}+\frac{p}{\frac{4}{3} \pi \cdot r_{p}^{3}} \cdot C_{\mathrm{sca}, p}
\end{aligned}
$$

\footnotetext{
* Corresponding author. Tel.: +33 661567 751; fax: +33 661556163 E-mail address: bdurand@chimie.ups-tlse.fr (B. Durand).
}

with $I_{1}$ and $I_{2}$ the light beam intensities before and after travelling through a sample of thickness $D ; R_{s}$ the total normal surface reflectance $\left(=0.14\right.$ for PCA); $\gamma_{\text {tot }}$ the total scattering coefficient; $r$ the average grain radius; $\Delta n$ the average refractive index change between two adjacent grains $\left(=0.005\right.$ for PCA), $\lambda_{0}$ the wavelength of incident light under vacuum; $p$ the total porosity, $r_{p}$ the average pore radius and $C_{\text {sca, },}$ the scattering cross section of one spherical pore [6,7]. As PCA is a birefringent material, the model predicts that to obtain high real in-line transmittance over the spectrum, both grain size $(<0.5 \mu \mathrm{m})$ and porosity $(<0.05 \%$ with a narrow distribution of nanometric pores) have to be carefully controlled. To do so, two strategies were combined: doping alumina with metal oxides (ppm range) and sintering the powders by Spark Plasma Sintering (SPS).

The effects of the doping elements on alumina have been studied for many years but are still the subject of diverse research. The first rule to control the densification of alumina is to start from a high purity powder. The process is very sensitive to impurities, especially silicon, calcium and sodium [8,9], which can lead to inhomogeneous densification with abnormal grain growth [9]. Small amounts of various doping oxides $\left(\mathrm{MgO}, \mathrm{La}_{2} \mathrm{O}_{3}, \mathrm{Y}_{2} \mathrm{O}_{3}\right)$ can be introduced in the alumina to have a better control of densification. Most of these doping agents, due 
to their very low solubility in alumina, segregate at grain boundaries during the sintering. Some Secondary-Ion Mass Spectrometry (SIMS) images illustrate this phenomenon very clearly; after densification, the doping agent $\left(\mathrm{MgO}, \mathrm{La}_{2} \mathrm{O}_{3}\right.$ and $\mathrm{Y}_{2} \mathrm{O}_{3}$ ) is located at grain boundaries and pore surfaces $[10,11]$. For $\mathrm{La}_{2} \mathrm{O}_{3}$ and $\mathrm{Y}_{2} \mathrm{O}_{3}$ doping, the segregation leads to an inhibition of grain growth and decreases the densification rate [11]. The rate-controller, during sintering of fine alumina, was reported by some authors to be grain boundary diffusion [1215]. Yoshida's group tried to explain how the doping elements act on grain boundary diffusivity. It is clear that the valence of the cation cannot explain this mechanism because $\mathrm{Pt}^{4+}$ increases the grain boundary diffusion while $\mathrm{Zr}^{4+}$ decreases it. According to the same authors, grain boundary diffusivity cannot be predicted by the size of the cation, but by ionicity in the vicinity of the grain boundaries. This ionicity improves the ionic bond strength and can limit atomic diffusion [16].

SPS is a processing technique that has been widely used over the past decades $[1,5,17-20]$. It was shown that dense, finegrained materials can be developed at low temperatures and short sintering times compared to conventional techniques such as hot isostatic pressing (HIP). Grain growth is then significantly reduced. Several studies have been performed over recent years to obtain transparent alumina by SPS. The heating rate has been found to be a critical parameter in obtaining such a material. According to Aman et al. [20], grainboundary diffusion probably dominates at low heating rates whereas grain coarsening, in respect of thermal equilibrium considerations, is unavoidable at high heating rates during the initial stages of low temperatures sintering. According to Kim et al. [1], when sintering at under $1250{ }^{\circ} \mathrm{C}$, rapid heating creates high defect concentrations inducing dynamic grain growth and thus decreasing the transparency of the material. The in-line transmission of pure PCA was increased by about $15 \%$ (up to $46 \%$ at a wavelength of $640 \mathrm{~nm}$ ) on decreasing the heating rate from 10 to $2{ }^{\circ} \mathrm{C} / \mathrm{min}$. Recently, Stuer et al. [5] increased the RIT of Spark Plasma Sintered PCA up to $57 \%$ at $640 \mathrm{~nm}$, by tridoping the powder with $\mathrm{Mg}$, La and $\mathrm{Y}$ which proves the benefit of combining the strategy of doping with SPS. However, their RIT values are still far from those found by Krell et al. [2] using HIP (72\% at $640 \mathrm{~nm})$. Green body shaping was shown to be of crucial importance by Krell et al. [21] for natural sintering. Recently, Aman et al. [22] have shown that processing the green state also has a strong influence on the optical properties of Spark Plasma Sintered PCA. However, some aspects of the powder preparation such as the thermal treatment before sintering and the nature of the starting salt, have not been studied yet. The aim of this work is to give a basic overview of the powder preparation parameters which can play a role during the Spark Plasma Sintering of transparent PCA.

\section{Experimental}

The starting material was a commercial (BA15PSH, Baïkowski) high purity $\alpha-\mathrm{Al}_{2} \mathrm{O}_{3}$ slurry (solid content $73.5 \mathrm{wt} \%$ ) with a median particle size $\mathrm{D}_{50}$ of $150 \mathrm{~nm}$. The total amount of impurity was less than $0.01 \mathrm{wt} \%$ (14 ppm Na,
60 ppm K, 7.1 ppm Fe, 13 ppm Si, 4 ppm Ca) as reported by the manufacturer.

The doping agents were introduced by weighing out the required amount of water-soluble salts (nitrates or chlorides) of lanthanum, zirconium and magnesium, pouring them into the alumina slurry and stirring for $24 \mathrm{~h}$ by rotation of the container. Then, the slurry was frozen in liquid nitrogen and freeze-dried for approximately $48 \mathrm{~h}\left(-40{ }^{\circ} \mathrm{C}, 0.1 \mathrm{mbar}\right.$, Alpha2-4, Christ). The resulting powders were sintered either as-obtained or after thermal pre-treatment to transform the salt into oxide, at 450, 500 and $650{ }^{\circ} \mathrm{C}$ for $\mathrm{Mg}, \mathrm{Zr}$ and La respectively, with no holding time.

The chosen doping agent amounts (wt ppm) were: 100, 200, 500 for $\mathrm{ZrO}_{2}, 100,200,500$ for $\mathrm{La}_{2} \mathrm{O}_{3}$ and 150, 300, 500 for $\mathrm{MgO}$. All ppm given in the following are expressed in weight.

Specific surface areas were measured by BET (Micromeritics FlowSorb II 2300), pore sizes were determined by mercury infiltration (Micromeritics Instrument Corp.) and TGA was performed using a Setaram TAG 24.

Densification was carried out by either conventional sintering or SPS. In the first case, $6 \mathrm{~mm}$ diameter pellets were uniaxially pressed at $200 \mathrm{MPa}$ for $2 \mathrm{~min}$ and sintered in a conventional furnace at $1350{ }^{\circ} \mathrm{C}$ in static air for $2 \mathrm{~h}$ at a heating rate of $200{ }^{\circ} \mathrm{C} / \mathrm{h}$ and then final densities were estimated from size and weight measurements. For SPS the powders were sieved $(<500 \mu \mathrm{m})$ and sintered (HP D 25/1, FCT System, Rauenstein, Germany) using the following cycle: applied uniaxial pressure of $80 \mathrm{MPa}$ throughout the cycle, rapid heating up to $800{ }^{\circ} \mathrm{C}$, a heating rate of $10{ }^{\circ} \mathrm{C} / \mathrm{min}$ from $800{ }^{\circ} \mathrm{C}$ to $1100{ }^{\circ} \mathrm{C}$ followed by a slower heating $\left(1^{\circ} \mathrm{C} / \mathrm{min}\right)$ up to the final sintering temperature $\left(T_{f}\right)$ in order to remove the residual porosity [1]. The final sintering temperature was in the range $1180-1280{ }^{\circ} \mathrm{C}$. Rapid cooling ended the cycle, interrupted by a 10-min dwell at $1000{ }^{\circ} \mathrm{C}$ to release the residual stresses [1]. Then, the samples were carefully mirror-polished on both sides using diamond slurries and the transparency was evaluated by a real in-line transmittance (RIT) measurement (Jasco V-670) which only takes into account the unscattered light passing straight through the sample (i.e. the real transmitted light) as explained by Apetz and van Bruggen [6]. All the RIT values given in this paper were measured at $\lambda=640 \mathrm{~nm}$ and Eq. (3) was used to obtain the RIT at the same thickness of $0.88 \mathrm{~mm}$ to compare the results:

$\operatorname{RIT}\left(t_{2}\right)=\left(1-R_{S}\right)\left(\frac{\operatorname{RIT}\left(t_{1}\right)}{1-R_{S}}\right)^{t_{2} / t_{1}}$

where $R_{S}$ is the total normal surface reflectance ( $=0.14$ for PCA) and RIT $\left(t_{i}\right)$ is the RIT for a sample of thickness $t_{i}$.

SETARAm Setsys evolution TMA-16/18 was used to carry out dilatometric measurements in air with a heating rate of $2.5^{\circ} \mathrm{C} /$ min and a final temperature of $1600{ }^{\circ} \mathrm{C}$.

SEM JEOL JSM-6510LV and SEM PhILIPS ESEM-FEG FEI XL30 were used to investigate the microstructure of the samples. The average line intercept method has been used to estimate grain sizes on fracture surfaces, applying a correction factor of 1.56 [23]. 
Table 1

RIT at $640 \mathrm{~nm}$ for $0.88 \mathrm{~mm}$ thick pellets and grain size of undoped ceramics sintered by SPS at different temperatures.

\begin{tabular}{|c|c|c|c|c|c|}
\hline Sintering temperature $\left({ }^{\circ} \mathrm{C}\right)$ & 1280 & 1250 & 1230 & 1200 & 1180 \\
\hline $\operatorname{RIT}(\%)(\lambda=640 \mathrm{~nm})$ & 18.9 & 23 & 30.5 & 27.4 & 33.6 \\
\hline Grain size $(\mu \mathrm{m})$ & $1.93 \pm 0.35$ & $1.50 \pm 0.23$ & $1.17 \pm 0.20$ & $0.80 \pm 0.19$ & $0.52 \pm 0.11$ \\
\hline
\end{tabular}

\section{Results and discussion}

\subsection{Effect of sintering temperature and doping}

As too high a temperature can cause grain growth during sintering, this parameter needs to be carefully controlled. Five samples of freeze dried pure alumina were sintered by SPS at different $T_{f}$ (1180-1200-1230-1250-1280 $\left.{ }^{\circ} \mathrm{C}\right)$. RIT and grain size were determined (Table 1). A maximum RIT of $33.6 \%$ was reached at $1180{ }^{\circ} \mathrm{C}$. But at this temperature and at $1200{ }^{\circ} \mathrm{C}$, a gradient of transparency was noted, indicating that the temperature was not the same at the centre (very dense and transparent) and at the edge (not dense and translucent) of the pellet [24-26]. The gradient was no longer observed for the sample sintered at $1230{ }^{\circ} \mathrm{C}$ which presented a high and homogeneous RIT of $30.5 \%$. Moreover, when comparing the RIT all over the spectrum (300-2500 nm) (Fig. 1), it appears that the RIT of the sample sintered at $1180{ }^{\circ} \mathrm{C}$ was lower than that of the sample sintered at $1230{ }^{\circ} \mathrm{C}$ in the IR wavelengths (at $\lambda=2000 \mathrm{~nm}, \quad \operatorname{RIT} \quad\left(1180{ }^{\circ} \mathrm{C}\right)=64.9 \%$ and RIT $\left.\left(1230{ }^{\circ} \mathrm{C}\right)=75.5 \%\right)$. The grain size of the ceramic increased regularly from 0.52 to $1.93 \mu \mathrm{m}$ as the temperature was raised from 1180 to $1280{ }^{\circ} \mathrm{C}$. This increase contributes to the decrease in RIT as the sintering temperature rises.

The measured RIT of samples sintered below $1230{ }^{\circ} \mathrm{C}$ were significantly lower than the theoretical values calculated for non-porous ceramics with the same grain size which corroborates the presence of residual porosity (Fig. 2). The RIT measured for ceramics sintered at 1230,1250 and $1280{ }^{\circ} \mathrm{C}$ were very close to the theoretical ones, so $1230{ }^{\circ} \mathrm{C}$ can be considered as the optimized sintering temperature. The SEM micrographs (Fig. 3) show that the grain size in all undoped ceramic samples was not homogeneous. The sample sintered at



Fig. 1. Whole spectrum (300-2500 nm) RIT of two undoped alumina samples, sintered at $1180{ }^{\circ} \mathrm{C}$ (grey) and $1230^{\circ} \mathrm{C}$ (black).
$1230{ }^{\circ} \mathrm{C}$, where the median grain size was $1.17 \mu \mathrm{m}$, exhibits grains with diameters ranging from $0.8 \mu \mathrm{m}$ to $1.5 \mu \mathrm{m}$.

The grain size and the transparency of the pure alumina sintered at $1230{ }^{\circ} \mathrm{C}$ are in good agreement with the results found by Kim et al. [18]. When the temperature was decreased to $1150{ }^{\circ} \mathrm{C}$, the transparency was improved in the visible range but decreased in the IR corroborating our results at $1180{ }^{\circ} \mathrm{C}$. These authors were also able to increase the transparency of $30 \mathrm{~mm}$ diameter pellets sintered at $1150{ }^{\circ} \mathrm{C}$ up to $47 \%$ and decrease grain size to $\sim 300 \mathrm{~nm}[1,17]$. However, these measurements were taken at the centre of the pellets. According to the same authors [18], rapid grain growth occurs in the centre of $30 \mathrm{~mm}$ diameter pellets compared to the outer part, probably resulting in inhomogeneous transparency of the samples. Decreasing the temperature is beneficial for a decrease in grain size and thus an increase in the RIT. But too low a temperature will lead to inhomogeneous samples. At low temperatures,



Fig. 2. Comparison of the RIT of pure alumina sintered by SPS with the theoretical curves $(\lambda=640 \mathrm{~nm}$ th $=0.88 \mathrm{~mm})$

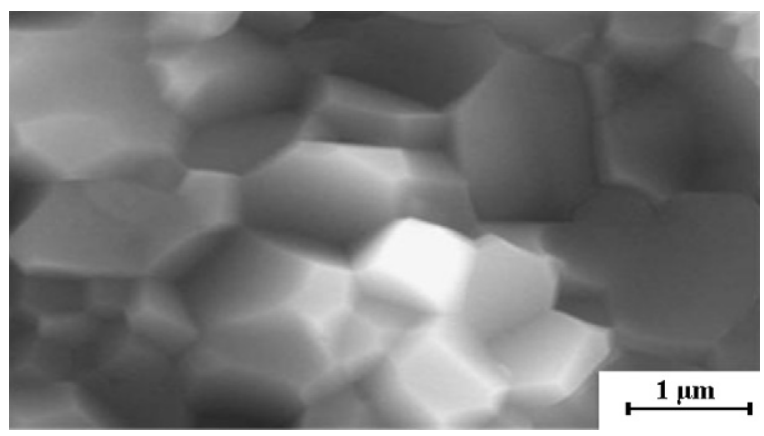

Fig. 3. SEM pictures of undoped alumina sintered by SPS at $1230{ }^{\circ} \mathrm{C}$. 
temperature gradient led to more porosity at the edge of the pellet explaining the loss of RIT. When increasing temperature, last porosities will shrink and an optimum between lower grain size with a higher amount of porosity at the edge and higher grain size with a lower amount of porosity at the centre will be found, explaining the homogenization of the RIT. Finally, when increasing again temperature, the same amount of porosity is found all over the sample. It means that the RIT difference is only due to grain size difference. This difference is decreasing when increasing grain size explaining why the samples are still homogeneous (Fig. 2). Optimizing temperature is a critical point to obtain an optimum between an homogeneous sample having a high RIT.

It has been proved over the past decades that the use of appropriate doping agents can decrease the grain size of sintered alumina and thus improve the RIT. Conventional sintering at $1350{ }^{\circ} \mathrm{C}$ for $2 \mathrm{~h}$ under static air was performed on 4 non-thermally pre-treated freeze-dried alumina powders: pure alumina and alumina doped with $\mathrm{Mg}^{2+}, \mathrm{Zr}^{4+}$ and $\mathrm{La}^{3+}$ nitrates. The relative density of the undoped ceramic was $93.8 \pm 0.5 \%$. For $\mathrm{MgO}$ doped ceramics, a regular increase of density was observed $(93.7 \pm 0.3 \%, 94.3 \pm 0.4 \%$ and $95.7 \pm 0.5 \%$ for 150 , 300 and 500 ppm respectively). With $\mathrm{ZrO}_{2}$ and $\mathrm{La}_{2} \mathrm{O}_{3}$, the inverse effect was noted: for $500 \mathrm{ppm} \mathrm{ZrO}_{2}$ and $\mathrm{La}_{2} \mathrm{O}_{3}$ the density was $92.3 \pm 0.5 \%$ and $93.1 \pm 0.8 \%$ respectively. These results indicate that $\mathrm{MgO}$ doping enhances the densification whereas $\mathrm{ZrO}_{2}$ and $\mathrm{La}_{2} \mathrm{O}_{3}$ reduce it at this sintering temperature. These results were confirmed by the dilatometric measurements that show that the densification of the $\mathrm{ZrO}_{2}$ and $\mathrm{La}_{2} \mathrm{O}_{3}$-doped samples begins at higher temperatures than that of $\mathrm{MgO}$-doped and undoped alumina samples (Fig. 4). The densification of the $\mathrm{MgO}$-doped samples began at nearly the same temperature as that of undoped samples but the shrinkage of MgO-doped ceramic was greater above $1280{ }^{\circ} \mathrm{C}$. The later of densification of $\mathrm{ZrO}_{2}$ and $\mathrm{La}_{2} \mathrm{O}_{3}$-containing samples is explained by the segregation of the doping agents at grain boundaries (in solid solution and/or as precipitates). Indeed some works have already reported this segregation for all the doping agents considered [10,12,27-31] during conventional sintering. Thus, the diffusion of the $\mathrm{Al}$ ions is reduced and grain boundary



Fig. 4. Dilatometric measurements under air of $500 \mathrm{ppm}$ doped alumina powders $\left(\mathrm{MgO}, \mathrm{ZrO}_{2}, \mathrm{La}_{2} \mathrm{O}_{3}\right)$ prepared with nitrate salts. sliding is limited. The result is controlled grain growth with densification at higher temperatures. This effect depends on the amount of doping agents included: as the dosage of doping agent decreased, the shrinkage curves became closer to those of undoped samples.

According to these results, optimizing the final temperature during the "SPS cycle" for each doping agent is necessary to achieve fully dense pellets.

\subsection{Effect of thermal pre-treatment of the powder}

Powders obtained by freeze-drying were thermally pretreated at temperatures corresponding to the thermal decomposition of the doping element salts (nitrates or chlorides) to yield oxides, i.e. $450,500,650$ and $700{ }^{\circ} \mathrm{C}$ for $\mathrm{Mg}$ (nitrate), $\mathrm{Zr}$ (nitrate and chloride), La (nitrate and chloride) and $\mathrm{Mg}$ (chloride) respectively, with no holding time. Preliminary thermal pre-treatment at $200{ }^{\circ} \mathrm{C}$ showed no influence on the specific surface areas (SSA) of powders which remained in the same range as those of non-thermally treated powders, 19$20 \mathrm{~m}^{2} \mathrm{~g}^{-1}$. Lower SSA, between 14 and $16 \mathrm{~m}^{2} \mathrm{~g}^{-1}$ were obtained after thermal pre-treatment at $650{ }^{\circ} \mathrm{C}$ without dwell. Thermal pre-treatment at $700{ }^{\circ} \mathrm{C}$ with $1 \mathrm{~h}$ dwell time weakly
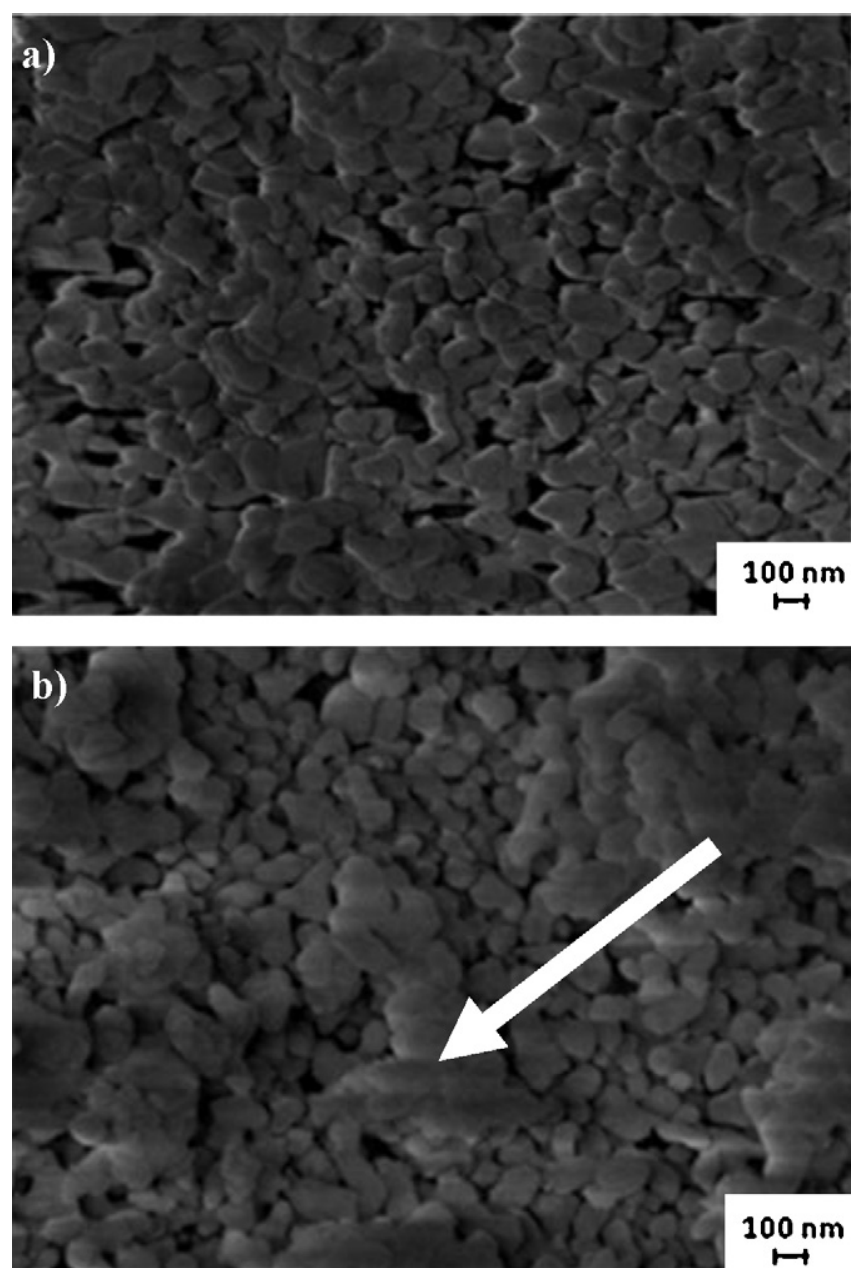

Fig. 5. SEM pictures of the freeze-dried $500 \mathrm{ppm} \mathrm{MgO-doped} \mathrm{alumina} \mathrm{powder}$ (a) non-thermally pre-treated (b) thermally pre-treated at $700{ }^{\circ} \mathrm{C}$ for $1 \mathrm{~h}$. 
decreased the SSA to $12-13 \mathrm{~m}^{2} \mathrm{~g}^{-1}$. SEM analyses showed that agglomeration appeared at this elevated temperature (Fig. 5). Porosity measurements by mercury infiltration were performed on $200 \mathrm{ppm} \mathrm{ZrO}_{2}$-doped alumina powder (nitrate based) either thermally pre-treated at $500{ }^{\circ} \mathrm{C}$ or not (Fig. 6a). Both powders presented the same range of intra-granular porosity $(20-60 \mathrm{~nm})$ indicating the same primary particle arrangement. However, bigger inter-granular porosity was found on thermally pretreated powder $(10-300 \mu \mathrm{m})$ indicating the presence of larger agglomerates. The two kinds of powders (thermally pre-treated or not) were then uniaxially pressed at $50 \mathrm{MPa}$. Fig. $6 \mathrm{~b}$ shows the subsequent results of mercury infiltration measurement. The larger agglomerates were no longer present in the thermally pre-treated sample after pressing but porosity $(100 \mathrm{~nm}-1 \mu \mathrm{m})$ was larger than that measured for the nonthermally treated samples $(<200 \mathrm{~nm})$. It is well known that large pores are harder to remove during sintering than small ones.

Three samples (undoped, $500 \mathrm{ppm} \quad \mathrm{ZrO}_{2}$-doped and $500 \mathrm{ppm} \mathrm{MgO}$-doped) were prepared with and without thermal pre-treatment at $650{ }^{\circ} \mathrm{C}$. Nitrate salts were used for the doping. After sintering in a conventional furnace at $1350{ }^{\circ} \mathrm{C}$, the



(b)

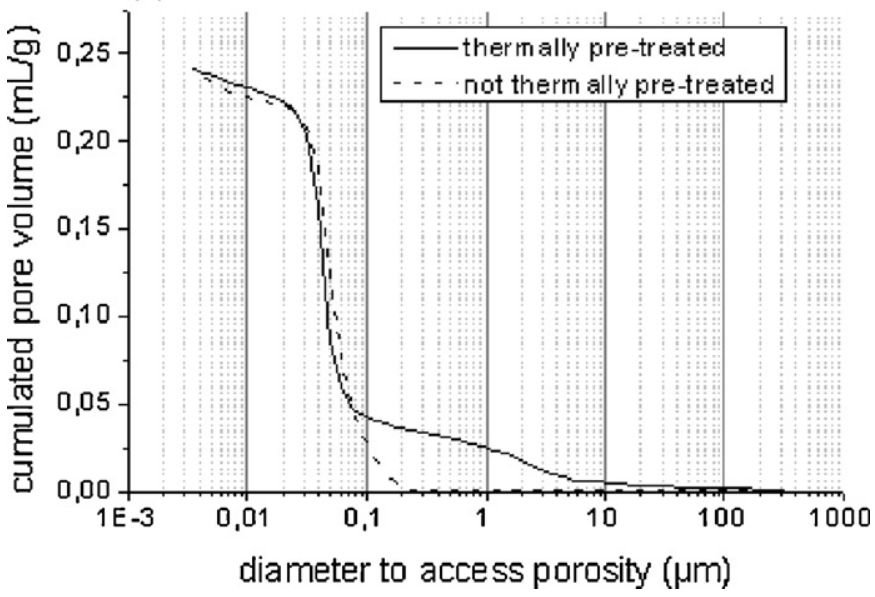

Fig. 6. Porosimetry measurement by mercury infiltration of a $200 \mathrm{ppm} \mathrm{ZrO}_{2}$ doped alumina powder (nitrate) (a) incremental pore volume of the powder (b) cumulated pore volume after pressing (50 MPa). relative densities of all thermally pre-treated samples were lower than those of the non-thermally treated samples. Thus, the density of the undoped samples fell from $93.8 \pm 0.5 \%$ to $87.2 \pm 0.2 \%$, that of the $\mathrm{MgO}$-doped samples from $95.7 \pm 0.1$ to $90.3 \pm 0.4$ and that of the $\mathrm{ZrO}_{2}$-doped samples from $92.3 \pm 0.5$ to $84.6 \pm 0.3$. When thermally pre-treating the powder, densification occurred at the same temperature as nonthermally pre-treated powder (Fig. 7) but the density of the green body was higher for non-thermally pre-treated samples leading to an improvement of densification (higher relative density throughout densification). Furthermore the higher green body density for non-thermally pre-treated powder was in good agreement with the mercury infiltration porosity measurements. Agglomeration during thermal pre-treatment led to poor particle packing so the pores were harder to remove during sintering as explained by Azar et al. [32].

\subsection{Nitrate or chloride doping salt effect}

Conventional sintering $\left(1350{ }^{\circ} \mathrm{C} / 2 \mathrm{~h}\right)$ was performed on $300 \mathrm{ppm} \mathrm{MgO}$-doped alumina and $200 \mathrm{ppm} \mathrm{ZrO}_{2}$-doped alumina, non thermally pre-treated. In both cases, two samples were prepared: one doped using the chloride salt and the other using the nitrate salt. The samples doped using chloride salts

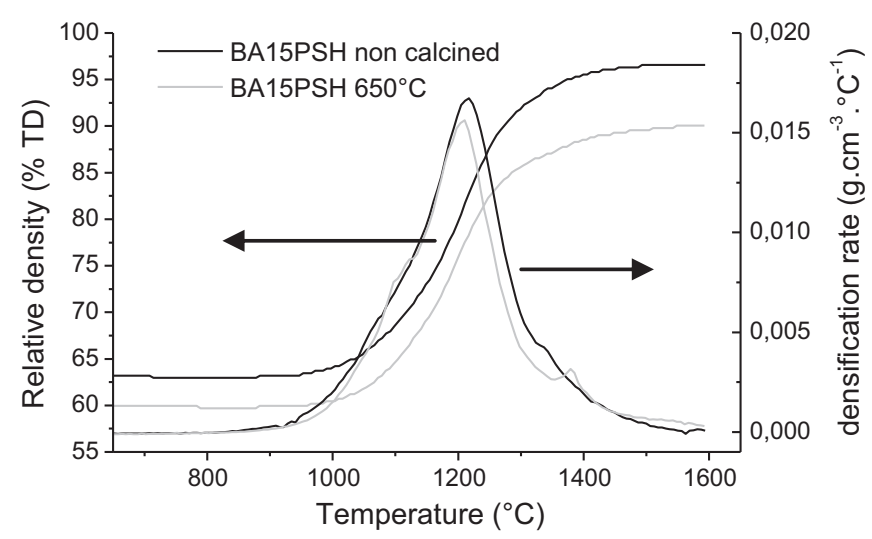

Fig. 7. Dilatometric measurements of pure freeze-dried alumina powders thermally pre-treated or not.



Fig. 8. Dilatometric measurement of non-thermally pre-treated alumina powders doped with $300 \mathrm{ppm}$ of either $\mathrm{Mg}$ nitrate or chloride salt. 


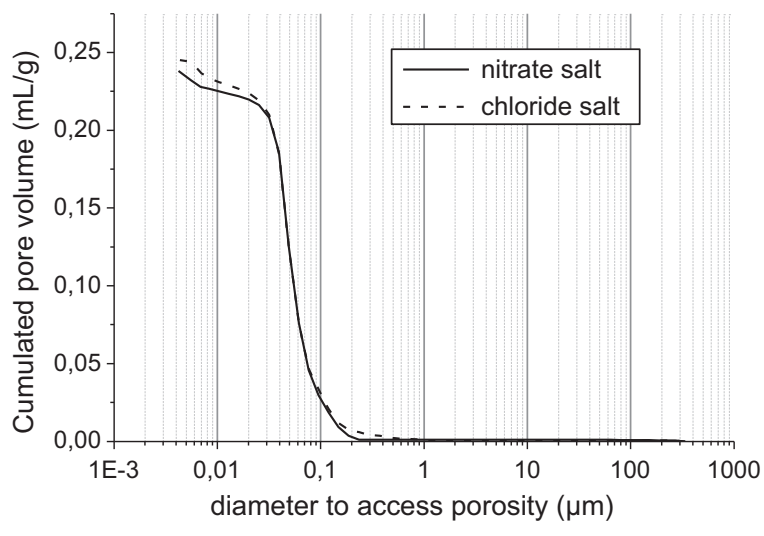

Fig. 9. Porosimetry measurement by mercury infiltration of non-thermally pretreated $200 \mathrm{ppm} \mathrm{ZrO}_{2}$-doped alumina powder (nitrate or chloride) - cumulated pore volume after pressing (50 $\mathrm{MPa})$.

exhibit slightly higher densities than those doped using nitrate salts $(96.1 \% \mathrm{TD}$ against $94.3 \% \mathrm{TD}$ for the $\mathrm{MgO}$-doped alumina and $94.9 \% \mathrm{TD}$ against $92.9 \% \mathrm{TD}$ for the $\mathrm{ZrO}_{2}$-doped alumina). The results are confirmed by the dilatometric curves (Fig. 8) as shown for the $\mathrm{MgO}$-doped sample: sintering occurred at the same temperature for both salts (nitrate and chloride), while doping with chloride salt slightly improved the relative density at the end of sintering. Moreover, 200 ppm $\mathrm{La}_{2} \mathrm{O}_{3}$-doped nonthermally treated alumina powders prepared either with nitrate



Fig. 10. Thermogravimetric measurements (TGA and DTG) of $2350 \mathrm{ppm} \mathrm{MgO}$ doped alumina (nitrate or chloride).

or chloride salts were sintered by SPS at a final temperature of $1280{ }^{\circ} \mathrm{C}$. For $\lambda=640 \mathrm{~nm}$ and a thickness of $0.88 \mathrm{~mm}$, the RIT measurement was slightly improved for the sample doped with chloride salt $(48.1 \%$ against $45.9 \%$ for sample doped with nitrate salt). Since the samples were not thermally pre-treated, chloride or nitrate ions may have played a role during the sintering.

To understand the slightly better sintering behaviour of samples prepared with chloride salt, porosity was measured by mercury infiltration on $200 \mathrm{ppm} \mathrm{ZrO}_{2}$-doped green bodies (non-thermally pre-treated powders were uniaxially pressed at

(a) 300ppm MgO-doping - RIT Measurement $(\lambda=640 \mathrm{~nm}-$ th. $=0.88 \mathrm{~mm})$

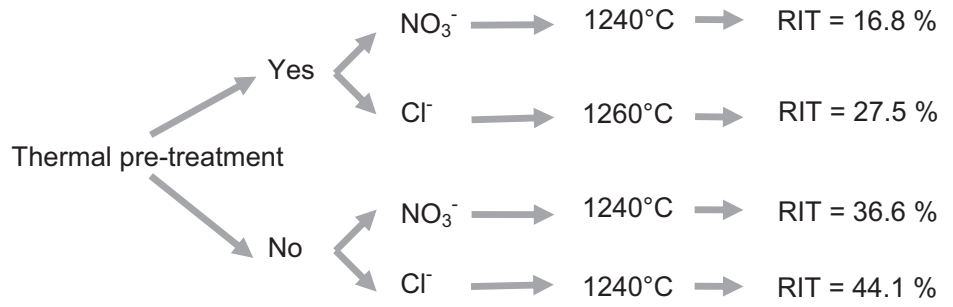

(b) 200ppm $\mathrm{ZrO}_{2}$-doping $-\mathrm{RIT}$ Measurement $(\lambda=640 \mathrm{~nm}-$ th. $=0.88 \mathrm{~mm})$

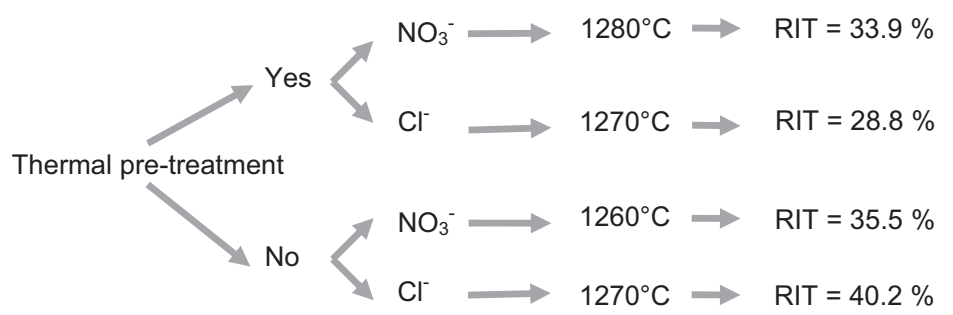

(c) 200ppm La $\mathrm{O}_{3}$-doping $-\mathrm{RIT}$ Measurement $(\lambda=640 \mathrm{~nm}-$ th. $=0.88 \mathrm{~mm})$

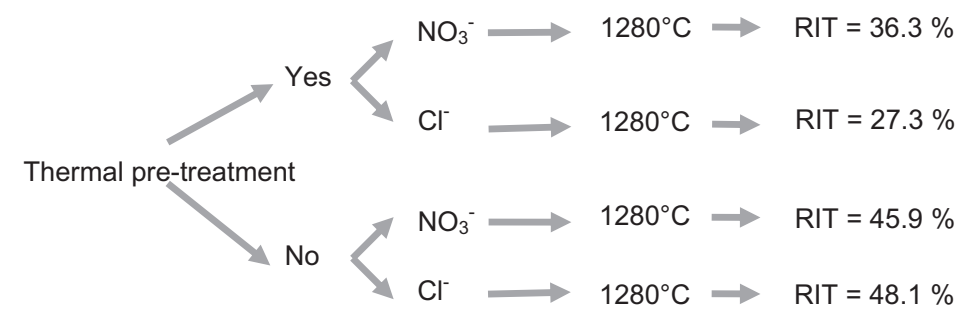

Fig. 11. RIT measurements $\left(\lambda=640 \mathrm{~nm}\right.$ th $=0.88 \mathrm{~mm}$ ) of (a) $300 \mathrm{ppm} \mathrm{MgO-doped} \mathrm{(b)} 200 \mathrm{ppm} \mathrm{ZrO}_{2}$-doped (c) $200 \mathrm{ppm} \mathrm{La}_{2} \mathrm{O}_{3}$-doped. 
$50 \mathrm{MPa}$ ) prepared either with nitrate or chloride salt. No significant difference was observed (Fig. 9) and sintering behaviour of powders doped with chloride salts cannot be explained by a better pressing behaviour or final packing homogeneity.

Thermogravimetric analysis under air at a heating rate of $2.5^{\circ} \mathrm{C} / \mathrm{min}$ was also performed on $2350 \mathrm{ppm} \mathrm{MgO}$-doped, $7250 \mathrm{ppm} \mathrm{ZrO}_{2}$-doped and $9650 \mathrm{ppm} \mathrm{La}_{2} \mathrm{O}_{3}$-doped alumina powders. Comparable behaviour was observed for the three doping elements. As shown in Fig. 10 for the $\mathrm{MgO}$-doped samples, the chlorides and the nitrates are transformed into oxides in the same temperature range. The main part of the weight loss occurs during the three steps below $350{ }^{\circ} \mathrm{C}$ and then the weight slowly and regularly decreases until it reaches a constant value at about $1000{ }^{\circ} \mathrm{C}$. The whole weight loss, close to $3 \mathrm{wt} \%$ was five to tenfold higher than that calculated for the transformation into oxide of the amount of doping chloride or nitrate, i.e. respectively 0.30 and $0.59 \mathrm{wt} \%$ for $\mathrm{MgCl}_{2}$ and $\operatorname{Mg}\left(\mathrm{NO}_{3}\right)_{2}$. Below $250{ }^{\circ} \mathrm{C}$, the two first losses are undoubtedly attributed to the release of adsorbed water and above $250{ }^{\circ} \mathrm{C}$ it is difficult to distinguish the end of dehydration and the start of decomposition of the doping salts. Although thermogravimetric investigation did not clarify the difference between nitrates and chlorides, doping with chloride salts enables slightly higher densities to be reached in natural sintering and a slightly better RIT after SPS sintering. Thus, it was decided to introduce doping elements into the slurry in the form of their chloride salt for the following steps of this study.

\subsection{Sintering optimization of doped powders}

Doped samples prepared with either chloride or nitrate salts (300 ppm $\mathrm{MgO}, 200 \mathrm{ppm} \mathrm{ZrO}_{2}, 200 \mathrm{ppm} \mathrm{La}_{2} \mathrm{O}_{3}$ ) either thermally pre-treated or not were sintered by SPS. Final sintering temperature was optimised for each doping agent as densification was delayed by their presence (fig. 4). RIT measurements were performed on these samples and the optimised results are given in Fig. 11. The results are in good agreement with those of the conventional sintering presented above. The SPS efficiency is also sensitive to the powder preparation, as previously shown in Section 3.2 for natural sintering. The presence of large agglomerates in the thermally pre-treated powder is detrimental to full densification of the ceramic. The residual porosity is associated to the former large inter-agglomerate pores, reducing the RIT value. Moreover, doping with chloride salt has slightly increased the RIT, as previously shown in Section 3.3, even though this effect was less pronounced than that of thermal pre-treatment. Finally, we were able to increase the RIT of doped-PCA up to $48.1 \%$ for $\mathrm{La}_{2} \mathrm{O}_{3}$-doped alumina.

The SEM micrographs of ceramics sintered at the optimised temperature for non-thermally pre-treated powders doped with chloride salts are reported in Fig. 12. All the doping agents led to a decrease in grain size $\left(\phi_{G}\right)$ compared to the freeze-dried pure alumina sintered at $1230^{\circ} \mathrm{C}$. $\left(\phi_{G}\right.$ was equal to $1.17 \pm 0.20$, $0.63 \pm 0.24,0.79 \pm 0.13,0.81 \pm 0.06 \mu \mathrm{m}$ respectively for pure, $\mathrm{MgO}, \mathrm{ZrO}_{2}, \mathrm{La}_{2} \mathrm{O}_{3}$-doped alumina). However, the grain


Fig. 12. SEM pictures of non-thermally pre-treated chloride based (a) $300 \mathrm{ppm}$

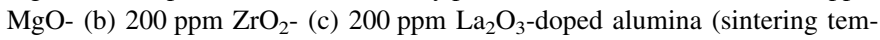
peratures are optimised). 




Fig. 13. Comparison of the RIT values of non-thermally pre-treated chloride based doped samples with the theoretical curves $(\lambda=640 \mathrm{~nm}$ th $=0.88 \mathrm{~mm})$.

size was still heterogeneous even though an improvement occurred especially for the $\mathrm{La}_{2} \mathrm{O}_{3}$-doped sample. Moreover, the porosity remaining in these doped samples, except for $\mathrm{La}_{2} \mathrm{O}_{3}$ samples, was in the same range as that of optimized pure alumina at close to $0.01 \%$ (Fig. 13). Finally $\mathrm{La}_{2} \mathrm{O}_{3}$ seems to be more efficient than the other doping agents at increasing the RIT of PCA but the underlying reasons are still under investigation.

The RIT value found for the $\mathrm{La}_{2} \mathrm{O}_{3}$-doped sample is close to that found by Stuer et al. [5] (50\% at $640 \mathrm{~nm}$ for a $\mathrm{La}_{2} \mathrm{O}_{3}$-doped sample with a thickness of $0.88 \mathrm{~mm}$ ) with a 20-min SPS cycle (heating rate $=100{ }^{\circ} \mathrm{C} / \mathrm{min}$ ) and a final temperature of $1350^{\circ} \mathrm{C}$. The cycle used in our study lasted $4 \mathrm{~h}$ to obtain high density at low temperature. We attempted to reproduce Stuer's results using his specific thermal cycle, but no transparency was found with cycles at temperatures higher than the one we optimised. This can be explained by the amount of doping agent used. Stuer doped alumina with 3.6 times more $\mathrm{La}_{2} \mathrm{O}_{3}$ than we did, probably delaying the sintering over $1250-1300{ }^{\circ} \mathrm{C}$. Another explanation can be found in the different size of the starting powder particles: around 5 times larger in Stuer's study. The higher particle size may delay sintering to higher temperatures.

Our RIT values can still be improved by optimizing the amount of each doping agent. This effect is currently under study.

\section{Conclusion}

Obtaining transparent polycrystalline alumina requires a very little amount of porosity and grains as fine as possible. This particular point can be achieved by both the use of doping agent and the SPS sintering technique for the densification of the sample as already published by Stuer et al. [5]. However, other parameters have to be optimised all over the process to avoid defects as agglomerates or porosity. In this study, the thermal pre-treatment, the nature of the doping salt and element and the sintering temperature have been investigated and their effects on the transparency of polycrystalline alumina (PCA) have been characterized. It has been shown that the sintering temperature has to be carefully optimised for each powder (doped or not) in order to obtain a homogeneous sample with a
RIT as high as possible. Then, for doped samples, the thermal pre-treatment will lead to the formation of agglomerates, decreasing the specific surface areas and increasing sample inhomogeneity, making densification harder and lowering the resulting RIT. Moreover, doping with chlorides instead of nitrates can help to slightly improve densification in conventional sintering and lead to a slight improvement of the RIT by SPS sintering.

Finally, each doping agent enables to increase the RIT of PCA at $640 \mathrm{~nm}\left(40.1 \%\right.$ for $\mathrm{ZrO}_{2}, 44.1 \%$ for $\mathrm{MgO}$ and $48.1 \%$ for $\mathrm{La}_{2} \mathrm{O}_{3}$ against $30.5 \%$ for pure alumina). If $\mathrm{La}_{2} \mathrm{O}_{3}$ appears to be the most efficient one, the reasons have not been determined yet and are still under investigation. Nevertheless, the results in this study should highlight the fact that each step of the process (from the powder preparation to the sintering of transparent polycrystalline alumina samples) has to be carefully optimised to avoid any defects as temperature/microstructure gradients, agglomeration or porosity which will induce a loss of RIT.

\section{Acknowledgements}

The authors are grateful for the financial support of the ANR Ceratrans and to all the participants, Lionel Bonneau (Baikowski), Johan Petit (ONERA), Stéphane Chaillot (BoosteC) and Denis Langlade (BTS Industrie).

\section{References}

[1] B.N. Kim, K. Hiraga, K. Morita, H. Yoshida, Effects of heating rate on microstructure and transparency of spark-plasma-sintered alumina, J. Eur. Ceram. Soc. 29 (2009) 323-327.

[2] A. Krell, J. Klimke, T. Hutzler, Advanced spinel and sub- $\mu \mathrm{m} \mathrm{Al}_{2} \mathrm{O}_{3}$ for transparent armour applications, J. Eur. Ceram. Soc. 29 (2009) 275-281.

[3] A. Krell, T. Hutzler, J. Klimke, Transmission physics and consequences for materials selection, manufacturing, and applications, J. Eur. Ceram. Soc. 29 (2009) 207-221.

[4] A. Krell, J. Klimke, T. Hutzler, Transparent compact ceramics: inherent physical issues, Opt. Mater. 31 (8) (2009) 1144-1150.

[5] M. Stuer, Z. Zhao, U. Aschauer, P. Bowen, Transparent polycrystalline alumina using spark plasma sintering: effect of $\mathrm{Mg}, \mathrm{Y}$ and La doping, J. Eur. Ceram. Soc. 30 (6) (2010) 1335-1343.

[6] R. Apetz, M.P.B. van Bruggen, Transparent alumina: a light-scattering model, J. Am. Ceram. Soc. 86 (3) (2003) 480-486.

[7] www.lightscattering.de/MieCalc/.

[8] S.J. Bennison, M.P. Harmer, Grain-growth kinetics for alumina in the absence of a liquid phase, J. Am. Ceram. Soc. 68 (1) (1985) C22-C24.

[9] S.J. Bennison, M.P. Harmer, Effect of $\mathrm{MgO}$ solute on the kinetics of grain growth in $\mathrm{Al}_{2} \mathrm{O}_{3}$, J. Am. Ceram. Soc. 66 (5) (1983) C90.

[10] A.M. Thompson, K.K. Soni, H.M. Chan, M.P. Harmer, D.B. Williams, J.M. Chabala, R. Levi-Setti, Dopant distributions in rare-earth-doped alumina, J. Am. Ceram. Soc. 80 (2) (1997) 373-376.

[11] K.K. Soni, A.M. Thompson, M.P. Harmer, D.B. Williams, J.M. Chabala, R. Levi-Setti, Solute segregation to grain boundaries in $\mathrm{MgO}$-doped alumina, Appl. Phys. Lett. 66 (21) (1995) 2795-2797.

[12] J. Fang, A.M. Thompson, M.P. Harmer, H.M. Chan, Effect of yttrium and lanthanum on the final-stage sintering behavior of ultrahigh-purity alumina, J. Am. Ceram. Soc. 80 (8) (1997) 2005-2012.

[13] K.A. Berry, M.P. Harmer, Effect of $\mathrm{MgO}$ solute on microstructure development in $\mathrm{Al}_{2} \mathrm{O}_{3}$, J. Am. Ceram. Soc. 69 (2) (1986) 143-149.

[14] A.H. Chokshi, An evaluation of the grain-boundary sliding contribution to creep deformation in polycrystalline alumina, J. Mater. Sci. 25 (7) (1990) 3221-3228. 
[15] J.D. Wang, R. Raj, Estimate of the activation energies for boundary diffusion from rate-controlled sintering of pure alumina, and alumina doped with zirconia or titania, J. Am. Ceram. Soc. 73 (5) (1990) 1172-1175.

[16] H. Yoshida, S. Hashimoto, T. Yamamoto, Dopant effect on grain boundary diffusivity in polycrystalline alumina, Acta Mater. 53 (2005) 433-440.

[17] B.N. Kim, K. Hiraga, K. Morita, H. Yoshida, Spark plasma sintering of transparent alumina, Scripta Mater. 57 (7) (2007) 607-610.

[18] B.N. Kim, K. Hiraga, K. Morita, H. Yoshida, T. Miyazaki, Y. Kagawa, Microstructure and optical properties of transparent alumina, Acta Mater. 57 (2009) 1319-1326.

[19] Z. Shen, et al., Spark plasma sintering of alumina, J. Am. Ceram. Soc. 85 (8) (2002) 1921-1927.

[20] Y. Aman, V. Garnier, E. Djurado, Spark plasma sintering kinetics of pure $\alpha$-alumina, J. Am. Ceram. Soc. 94 (4) (2011).

[21] A. Krell, P. Blank, H. Ma, T. Hutzler, M. Nebelung, Processing of highdensity submicrometer A12O3 for new applications, J. Am. Ceram. Soc. 86 (4) (2003) 546-553.

[22] Y. Aman, V. Garnier, E. Djurado, Influence of green state processes on the sintering behaviour and the subsequent optical properties of spark plasma sintered alumina, J. Eur. Ceram. Soc. 29 (2009) 3363-3370.

[23] M.I. Mendelson, Average grain size in polycrystalline ceramics, JACS 52 (1969) 443-446.

[24] K. Vanmeensel, A. Laptev, J. Hennicke, J. Vleugels, O. Van der Biest, Modelling of the temperature distribution during field assisted sintering, Acta Mater. 53 (2005) 4379-4388.
[25] U. Anselmi-Tamburini, S. Gennari, J.E. garay, Z.A. Munir, Fundamental investigations on the spark plasma sintering/synthesis process II. Modelling of current and temperature distributions, Mater. Sci. Eng. A 394 (2005) 139-148.

[26] S. Muñoz, U. Anselmi-Tamburini, Temperature and stress field evolutions in spark plasma sintering, J. Mater. Sci. 45 (2010) 6528-6539.

[27] J.T. Lin, H.Y. Lu, Grain growth inhibition and mechanical property enhancement by adding $\mathrm{ZrO}_{2}$ to $\mathrm{Al}_{2} \mathrm{O}_{3}$ matrix, Ceram. Int. 14 (1988) 251-258.

[28] D. Monceau, C. Petot, G. Petot-Ervas, J.W. Fraser, M.J. Graham, G.I. Sproule, Surface segregation and morphology of Mg-doped $\alpha$-alumina powders, J. Eur. Ceram. Soc. 15 (1995) 851-858.

[29] H. Yoshida, Y. Ikuhara, T. Sakuma, Grain boundary electronic structure related to the high temperature creep resistance in polycrystalline $\mathrm{Al}_{2} \mathrm{O}_{3}$, Acta Mater. 50 (2002) 2955-2966.

[30] H. Yoshida, Y. Ikuhara, T. Sakuma, Vacancy effect of dopant cation on the high-temperature creep resistance in polycrystalline $\mathrm{Al}_{2} \mathrm{O}_{3}$, Mater. Sci. Eng. A 319-321 (2001) 843-848.

[31] J. Cho, M.P. Harmer, H.M. Chan, J.M. Rickman, A.M. Thompson, Effect of yttrium and lanthanum on the tensile creep behavior of aluminum oxide, J. Am. Ceram. Soc. 80 (4) (1997) 1013-1017.

[32] M. Azar, P. Palmero, M. Lombardi, V. Garnier, L. Montanaro, G. Fantozzi, J. Chevalier, Effect of initial particle packing on the sintering of nanostructured transition alumina, J. Eur. Ceram. Soc. 28 (2008) 1121-1128. 